\title{
Shape-shift contagion in emerging markets equities: Evidence from frequency- and time-domain analysis
}

\author{
Peterson Owusu Junior* • Imhotep Alagidede • George Tweneboah
}

Wits Business School, University of the Witwatersrand, Johannesburg, South Africa

Received: 1 November 2019

Revised: 10 December 2019

Accepted: 20 January 2020

\begin{abstract}
We explore interdependence and contagion in the top 9 emerging markets and the US equities using a novel time-varying generalised lambda distribution (GLD)-based Baruník \& Křehlík (2018) (BK18) spillover technique. The GLD accounts for the extreme returns while the BK18 capture the nonlinear, nonstationary, asymmetric, and time-dependent comovements in higher moments. We find dominance of some emerging markets instead of the US in the frequencydependent spillovers. We also establish shape shift-contagion in emerging markets equities in the short-term. Our results shed new light on the sources of connectedness and contagion through the shape parameters of equity returns.
\end{abstract}

Keywords: shape parameters; lambda distribution; variance decomposition; emerging markets JEL Classification Codes: C1, C5, C14

\section{Introduction}

Interdependence and contagion have been explored for many years, particularly since the Asian Russian, Mexican, and Brazilian crises in the late 1980s and 1990s (Diebold \& Yilmaz, 2009). Financial markets connectedness also have unavoidable implications for risk management and policy decisions, among others. An ongoing debate has bordered on whether a spillover constitutes interdependence or contagion (Forbes \& Rigobon, 2002).

The extant literature emphasise the importance of higher moments in risk analysis and portfolio diversification (Bessembinder, 2018; Martellini \& Ziemann, 2010; Müller \& Wagner, 2018), among others. However, the literature is scanty on the origins of connectedness through higher moments of returns (see, Fry-McKibbin, Hsiao, \& Martin, 2017; Chan, Fry-McKibbin, \& Hsiao, 2019). Especially in the context of emerging markets (EMs) equities the literature is nonexistent. We deem this paper an important addition to the literature on EMs, contagion and spillover in general.

\footnotetext{
*Corresponding author. E-mail: 1986355@students.wits.ac.za.

Citation: Owusu Junior, P., Alagidede, I., and Tweneboah, G. (2020) Shape-shift contagion in emerging markets equities: Evidence from frequency- and time-domain analysis, Economics and Business Letters, 9(3), 146-156.
}

DOI: 10.17811/ebl.9.3.2020.146-156 
We examine the sources of interdependence and contagion through the shape parameters of a sampled EMs equities. To this end, we estimate rolling skewness and kurtosis values from the Freimer, Kollia, Mudholkar, \& Lin (1988) generalised lambda distribution (FKML-GLD) and apply the frequency-and time-domain connectedness of Baruník \& Křehlík (2018) (BK18) technique to these series. The GLD is selected for its mathematical simplicity and adequacy to easily fit extreme tails of data (Karian \& Dudewicz, 2016; Su, 2007). The BK18 is able to capture time-varying instability, nonlinearity, and nonstationarity in the returns. Dealing with nonlinearity, asymmetries have become increasing important in contagion studies. For instance, Bampinas \& Panagiotidis (2017) employ the local Gaussian correlation to capture nonlinearities between US stock markets and 1-4 months maturities of West Texas Intermediate (WTI) daily spot and futures crude oil prices (see also, Bae, Karolyi, \& Stulz, 2003; Baur, 2013; Bodart \& Candelon, 2009). The time-varying feature of the BK18 also appeals to the heterogeneous market hypothesis (HMH) (Müller et al., 1993) and prompts the need to delineate return series into short-, medium-, and long-term horizons to suit different investment preferences. In so doing, we contribute to the literature by hypothesising shape shift-contagion (SSC) as an extension of Forbes \& Rigobon's (2002) shift-contagion.

Thus, we analyse comoments (coskewness and cokurtosis ${ }^{1}$ ) in the narrow sense of using comovement in skewness and kurtosis of the selected EMs equities to examine their interdependence and contagion. The BK18 enables us to measure contagion in similar fashions as Forbes \& Rigobon (2002) (i.e. a sharp increase in cross-market spillovers at some frequency band(s)) (see; Saiti, Bacha, \& Masih, 2016; Diebold \& Yilmaz, 2009). With both time- and frequency-domain examination of higher moments' connectedness, we provide fresh evidence in the interdependence and contagion literature.

Our results indicate that spillovers are time-varying and frequency-dependent across the system for both asymmetric and extreme returns shock propagation. Contagious episodes are shortlived and "delayed" after the global financial crisis (GFC). Further, the US, however, a net transmitter of shocks does not dominate in spillovers, but South Korea, Brazil, and Mexico dominate the other markets at some frequency bands.

\section{Methodology}

We combine time-varying FKML-GLD and BK18 to investigate SSC in the selected EMs equities. We extract the daily one-month rolling shape parameters (lambda 3 (L3) for skewness and lambda 4 (L4) for kurtosis) estimates. The rolling BK18 technique decomposes the series into frequency-domain to permit the examination of connectedness at higher and lower frequencies over time.

\subsection{The GLD}

The GLD (Ramberg \& Schmeiser, 1974) is an inverse distribution function of Tukey's lambda (TL) distribution given as

$$
X=Q(U)=\left\{\begin{array}{c}
\frac{\left[U^{\lambda}-(1-U)^{\lambda}\right]}{\lambda}, \lambda \neq 0 \\
\frac{\log U}{1-U}, \lambda=0
\end{array}\right.
$$

where $U$ a uniform $(0,1)$ random variable and the transformation $Q(*)$, referred to as the quantile function, yields $Q(\alpha)$ as the $\alpha^{\text {th }}$ quantile $(0<\alpha<1)$ or $100 \alpha^{\text {th }}$ percentile of the distribution of $X$. The FKML-GLD, given $\lambda_{4}>0$, is defined over all $\lambda_{3}$ and $\lambda_{4}$ as

\footnotetext{
${ }^{1}$ Comoment, coskewness, and cokurtosis are not defined in strong mathematical and statistical terms as in, for instance, Fry-McKibbin, Hsiao, \& Martin, (2017). We define these as the connectedness of the higher moments among the 10 markets with BK18 spillover index.
} 


$$
F^{-1}(\rho \mid \lambda)=\lambda_{1}+\frac{\left[\frac{\rho^{\lambda_{3}-1}}{\lambda_{3}}-\frac{(1-\rho)^{\lambda_{4}-1}}{\lambda_{4}}\right]}{\lambda_{2}},
$$

where $\rho$ are the probabilities $\rho \in[0,1], \lambda_{1}, \lambda_{2}$ are location and $\lambda_{3}, \lambda_{4}$ represent shape parameters, respectively. The probability density function at $x=F^{-1}(\rho \mid \lambda)$ is given as

$$
f(x)=f\left(F^{-1}(\rho \mid \lambda)\right)=\frac{\lambda_{2}}{\lambda_{3} \rho^{\lambda_{3}-1}-\lambda_{4}(1-\rho)^{\lambda_{4}-1}}
$$

where parameter combinations of $\lambda$ must yield $f(x) \geq 0$ and $\int f(x) d x=1$ (Pfaff, 2016). In estimating the parameters, we have employed rolling window technique. For daily moments, we partition the series into $k=N-m+1$ subsamples where $m=20$ denotes the window length, and $N$ denotes sample size.

\subsection{The Barunik \& Krehlik (2018) spillover index}

The BK18 measures connectedness using generalised forecast error variance decompositions (GFEVDs). It is based on the matrix of a vector autoregressive (VAR) Eq. 4 model of local covariance stationarity. Let $K$-variate process $Y_{t}=\left(y_{1, t}, \ldots, y_{K, t}\right)^{\prime}$ at $t=1, \ldots, T$ and a $\operatorname{VAR}(\rho)$ may be represented as

$$
Y_{t}=\sum_{i=1}^{p} \phi_{i} y_{t-i}+\epsilon_{t}
$$

where $\phi_{i}$ and $\epsilon_{i}$ are coefficient matrices and white noise with (likely non-diagonal) covariance matrix $\Pi$. It is useful to work with a $(K \times K)$ matrix $\left(\boldsymbol{I}_{K}-\emptyset_{1} L-\cdots-\emptyset_{p} L^{p}\right)$ with identity $\boldsymbol{I}_{\boldsymbol{K}}$. If the roots of the characteristic equation $|\theta(z)|$ lie outside of the unit circle, the VAR system has a moving average $M A(\infty)$

$$
Y_{t}=\psi(L) \epsilon_{t},
$$

with $\psi(L)$ being an infinitely lagged polynomial. The GFEVD, the contribution of the kth variable to the variance of forecast error of the element $j$ can be written as

$$
\left(\Theta_{H}\right)_{j, k}=\frac{\sigma_{k k}^{-1} \sum_{h=0}^{H}\left(\left(\psi_{h} \Pi\right)_{j, k}\right)^{2}}{\sum_{h=0}^{H}\left(\psi_{h} \Pi_{h^{\prime}}\right)_{j, k}}
$$

where $h=1, \ldots, H$ and $\sigma_{k k}=\left(\Pi_{k k}\right)$. This is possible because the connectedness measure depends on variance decompositions, being the transformations of $\psi_{h}$ and serves as contribution of the shocks to the system. Since contributions in the row do not sum to unity, the matrix $\Theta_{H}$ is standardized as

$$
\left(\widetilde{\Theta}_{H}\right)_{j, k}=\frac{\left(\Theta_{H}\right)_{j, k}}{\sum_{k=1}^{N}\left(\Theta_{H}\right)_{j, k}}
$$

For total connectedness, the pairwise connectedness Eq. 7 can be aggregated, and defined as the share of variance in the forecasts contributed by errors other than own error or the ratio of the sum of the off-diagonal elements to the sum of the entire matrix (Diebold \& Yilmaz, 2012) as

$$
C_{H}=100 * \frac{\sum_{j \neq k}\left(\widetilde{\Theta}_{H}\right)_{j, k}}{\sum \widetilde{\Theta}_{H}}=100 *\left(1-\frac{\operatorname{Tr}\left\{\widetilde{\Theta}_{H}\right\}}{\sum \widetilde{\Theta}_{H}}\right),
$$

where $\operatorname{Tr}\{$.$\} is the trace operator, denominator is the arithmetic sum of all elements in the$ matrix. Bi-directional ("to" market $i$ from all other markets $k$, and vice versa ("from")) 
connectedness can be measured. From these "net" connectedness is also measured as the difference between "to" spillovers and "from" spillovers. Hence a market with a positive net spillover is a net transmitter while the one with a negative spillover is a net recipient of shocks.

In spectral representation, a frequency response function $\psi(e)^{-i \omega}=\sum_{h} e^{-i \omega h} \psi_{h}$ of Fourier transformable coefficients $\psi_{h}$ with $i=\sqrt{-1}$, a density of $Y_{t}$ at frequency $\omega$ can be defined as $M A(\infty)$ filtered series

$$
S_{y(\omega)}=\sum_{h=-\infty}^{\infty} E\left(Y^{\prime} Y_{t-h}\right) e^{-i \omega h}=\psi\left(e^{-i \omega}\right) \Pi \psi^{\prime}\left(e^{+i \omega}\right) .
$$

The power spectrum $S_{y(\omega)}$ describes the distribution of the variance of $Y_{t}$ over the frequency components $\omega$. The causation spectrum over $\omega \in(-\pi, \pi)$ is defined as

$$
(\mathcal{F}(\omega))_{j, k}=\frac{\sigma_{k k}^{-1}\left|\psi\left(e^{-i \omega}\right) \Pi_{j, k}\right|^{2}}{\left(\psi\left(e^{-i \omega}\right) \Pi \psi^{\prime}\left(e^{+i \omega}\right)\right)_{j, j}}
$$

noting that it represents the portion of the ith variable due to shocks in the $k t h$ variable at a given frequency $\omega$. It follows that $(\mathcal{F}(\omega))_{j, k}$ can be interpreted as within-frequency causation on account of the denominator.

In practically finance, it is better to measure connectedness over time horizons (i.e. bands $d=$ $(a, b): a, b \in(-\pi, \pi), a<b))$ as opposed to a single frequency point. A scaled 2 decomposition over $d$ can be defined as

$$
\left(\widetilde{\Theta}_{d}\right)_{j, k}=\left(\Theta_{d}\right)_{j, k} / \sum_{k}\left(\Theta_{\infty}\right)_{j, k}
$$

Subsequently, the within-frequency and frequency connectedness are defined in Eq. 12 and Eq. 13, respectively.

$$
\begin{aligned}
& C_{d}^{W}=100 *\left(1-\frac{\operatorname{Tr}\left\{\widetilde{\Theta}_{d}\right\}}{\sum \widetilde{\Theta}_{d}}\right) \\
& C_{d}^{F}=100 *\left(\frac{\sum \widetilde{\Theta}_{d}}{\sum \widetilde{\Theta}_{\infty}}-\frac{\operatorname{Tr}\left\{\widetilde{\Theta}_{d}\right\}}{\sum \widetilde{\Theta}_{\infty}}\right)=C_{d}^{W} *\left(\frac{\sum \widetilde{\Theta}_{d}}{\sum \widetilde{\Theta}_{\infty}}\right)
\end{aligned}
$$

We use the frequency bands $(\pi+0.00001, \pi / 64,0)$ which correspond to intraweek (shortterm) and quarter and beyond (long-term) periods (see Baruník \& Křehlík, 2018; Tiwari, Cunado, Gupta, \& Wohar, 2018; Tiwari, Shahbaz, Hasim, \& Elheddad, 2019).

\section{Data}

Our data comprises daily one-month rolling estimates of L3 and L4 from 01/01/2001 to 18/02/2019. Our data was gleaned from Bloomberg Terminal which are the top ${ }^{3} 9$ Morgan Stanley Capital International (MSCI) EMs and US equity indices. The US is deemed the originator of the 2007-2009 GFC (Mollah et al., 2016). It is only appropriate that the comovements of asymmetric (skewness) and extreme (kurtosis) returns in EMs are examined by including the US index. A 100-day ahead forecast horizon $(H)$ and a rolling window 100 days are used. That representing about one-quarter of a year and it is enough to account for time-variations. The rolling window mechanism avoids the need to exogenously specify crisis

\footnotetext{
${ }^{2}$ Scaling factor is 100 . It's also the minimum forecast horizon $H$ and rolling window size to implement the BK18 framework.

${ }^{3}$ https://www.msci.com/emerging-markets, as of March 29, 2019.
} 
Table 1. Summary statistics of selected EMs and US equities.

\begin{tabular}{crrrrr}
\hline \hline Market & China & S. Korea & Taiwan & India & Brazil \\
\hline Obs. & \multicolumn{5}{c}{ Panel A } \\
Mean & 4666 & 4666 & 4666 & 4666 & 4666 \\
Variance & 0.0003 & 0.0004 & 0.0001 & 0.0003 & 0.0002 \\
Skewness & 0.0003 & 0.0003 & 0.0002 & 0.0003 & 0.0005 \\
Kurtosis & -0.11 & -0.19 & -0.12 & -0.10 & -0.26 \\
Normtest.W* & 6.35 & 15.08 & 2.81 & 9.55 & 6.85 \\
\hline L3 & 0.93 & 0.91 & 0.96 & 0.92 & 0.94 \\
\hline Obs. & \multicolumn{5}{c}{ Panel B } \\
Mean & 4530 & 4530 & 4530 & 4530 & 4530 \\
Variance & 0.45 & $-2 \mathrm{E}+15$ & 0.43 & 0.48 & 0.49 \\
Normtest.W & 0.28 & $1.85 \mathrm{E}+34$ & 0.34 & 0.28 & 0.25 \\
\hline L4 & 0.95 & 0.03 & 0.94 & 0.95 & 0.96 \\
\hline Obs. & \multicolumn{5}{c}{ Panel C } \\
Mean & 4530 & 4530 & 4530 & 4530 & 4530 \\
Variance & 0.48 & $1.01 \mathrm{E}+15$ & 0.42 & 0.52 & 0.53 \\
Normtest.W & 0.31 & $4.62 \mathrm{E}+33$ & 0.33 & 0.30 & 0.30 \\
\hline \hline
\end{tabular}

start and end periods. We are able to account for major changes in the shape spillovers (by plotting the resulting spillover indices) sample period (Yilmaz, 2010).

\section{Results}

\subsection{Descriptive statistics}

In Table 1 (Panel A) skewness and kurtosis values indicate non-normality and leptokurtic behaviour across the board. We also find that rolling L3 and L4 estimates are non-Gaussian for all the markets (Panel B). We observe an extremely large negative of L3 (-9.2E+18) and equally large mean $(-2 \mathrm{E}+15)$ and variance $(1.85 \mathrm{E}+34)$ values. Similar deductions can be made for L4. Hence, chances are, the GLD better estimates the moments of the series than the Gaussian distribution. The Shapiro-Wilk test confirms these by rejecting the normality assumption. All series pass the Augmented Dickey-Fuller (ADF)-Generalised Least Squares (GLS) KwiatkowskiPhillips-Schmidt-Shin (KPSS) stationarity ${ }^{4}$ tests.

\subsection{Frequency-domain (static) analysis}

The static within (WTH) and absolute (ABS) spillovers are shown in Table 2 for both skewness (Panel A) and kurtosis (Panel B). The $i j t h$ entry is the spillover from market $i$ to market $j$. Diagonal entries $(i=j)$ indicate the fraction of the forecast error variance of market $i$ from its own shocks. We find that within connectedness are larger than absolute connectedness across the board. For every absolute connectedness value, there is a corresponding value within connectedness to indicate causality.

In Panel A, we find that the spillover among the 10 markets is stronger in the long-terms (dominated by Mexico) than in the short-term (dominated by South Korea). In Panel B, longterm connectedness is stronger (led by Mexico) than short-term (jointly led by Brazil and Mexico). We see both large and small markets dominating causal spillovers. A large market like South Korea dominates asymmetric (skewness) spillovers in the short-term while relatively small markets (Brazil and Mexico) lead in both asymmetric and extreme (kurtosis) returns spillovers. Also, the US is a net transmitter of shocks, but does not dominate in the propagation

\footnotetext{
${ }^{4}$ Not presented. The BK18, however, works on local stationarity (i.e. is stationarity within a neighbourhoods (frequency bands). This can be likened to the local Gaussian approximation and local correlation (see Bampinas \& Panagiotidis, 2017; Støve, Tjøstheim, \& Hufthammer, 2014).
} 
Table 1 (cont'd). Summary statistics of selected EMs and US equities.

\begin{tabular}{crrrrr}
\hline \hline Market & S. Africa & Rusia & Mexico & Thailand & US \\
\hline Obs. & \multicolumn{5}{c}{ Panel A } \\
Mean & 4666 & 4666 & 4666 & 4666 & 4666 \\
Variance & 0.0002 & 0.0003 & 0.0002 & 0.0004 & 0.0002 \\
Skewness & 0.0003 & 0.0005 & 0.0003 & 0.0002 & 0.0001 \\
Kurtosis & -0.29 & -0.43 & -0.17 & -0.49 & -0.24 \\
Normtest.W* & 4.02 & 13.55 & 6.88 & 9.38 & 9.34 \\
\hline L3 & 0.96 & 0.89 & 0.93 & 0.93 & 0.90 \\
\hline Obs. & \multicolumn{5}{c}{ Panel B } \\
Mean & 4530 & 4530 & 4530 & 4530 & 4530 \\
Variance & 0.53 & 0.48 & 0.49 & 0.50 & 0.46 \\
Normtest.W & 0.25 & 0.34 & 0.28 & 0.34 & 0.28 \\
\hline L4 & 0.96 & 0.94 & 0.96 & 0.90 & 0.96 \\
\hline Obs. & \multicolumn{5}{c}{ Panel C } \\
Mean & 4530 & 4530 & 4530 & 4530 & 4530 \\
Variance & 0.57 & 0.48 & 0.49 & 0.41 & 0.48 \\
Normtest.W & 0.26 & 0.34 & 0.25 & 0.28 & 0.26 \\
\hline \hline
\end{tabular}

of spillovers contrary to many findings (see, Boubaker, Jouini, \& Lahiani, 2016; Meinusch, 2017; Shahzad, Nor, Kumar, \& Mensi, 2017; Wang et al., 2017). Again, spillovers are frequency-dependent in magnitude and sign (positive/negative).

\subsection{Rolling (time-frequency-domain) analysis}

This accounts for time evolution of total connectedness and helps to determine the existence of contagion or otherwise. The results are presented in Figure 1 for skewness and kurtosis. For skewness (a), overall connectedness increases in magnitude and frequency, fluctuating around $2 \%$ to $7 \%$ in the short-term and around $1 \%$ to $65 \%$ in the long-term. We detect contagion around middle of 2017. But in the long-term, spillovers are high (about 50\%) on average over the periods, so interdependence suffices.

Extreme return (b) spillovers also follow an upward trend with frequencies. The markets are strongly connected and more contagious by extreme returns than by asymmetric returns. We observe contagious episodes around late 2016 in the short-term (a connectedness of about $90 \%$ compared to about $5 \%$ average) and about $25 \%$ in early 2018 . We rule out contagion in the long-term for kurtosis.

Compositely, contagious episodes are in the short-term and short-lived but only interdependence exists in the long-term for both skewness and kurtosis. The approximate contagion dates are removed from the GFC and Eurozone crisis. These corroborate the delayed contagion hypothesis of Boako \& Alagidede (2016). We also confirm Forbes \& Rigobon's (2002) shift-contagion. More importantly, our shape shift-contagion hypothesis is adequately established. Hence, we have established delayed-shape shift-contagion. We can conclude from these results that while financial crises episodes pose immediate threat to many markets, it is also important that traders and policy makers focus on spillovers for longer periods in the aftermath of these crises.

\section{Concluding remarks}

We introduced a GLD-based BK18 analysis of higher moments to examine connectedness in EMs and US equities. We found that spillovers increase through time with South Korea (shortterm), Brazil (short-term), and Mexico (both short- and long-terms) dominating rather than the US. However, the US is only a net transmitter of shocks but never a net recipient across the board. One can surmise that emerging market economies are to be cautious of the policy 
Figure 1. Overall rolling spillovers between higher moments of the top 9 EMs and US equities.

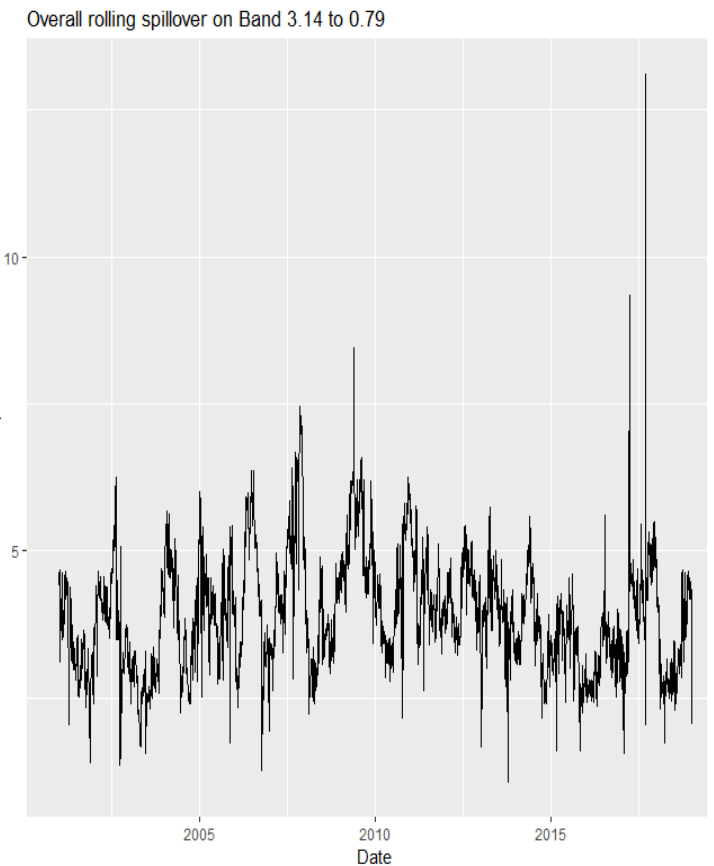

(a) Skewness (L3)

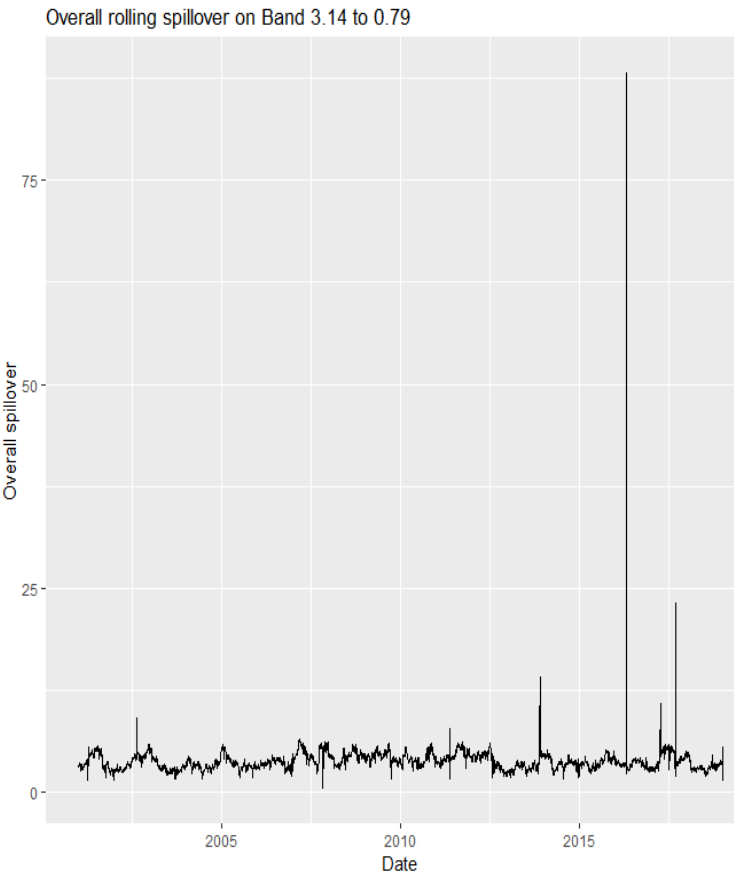

(b) Kurtosis (L4)

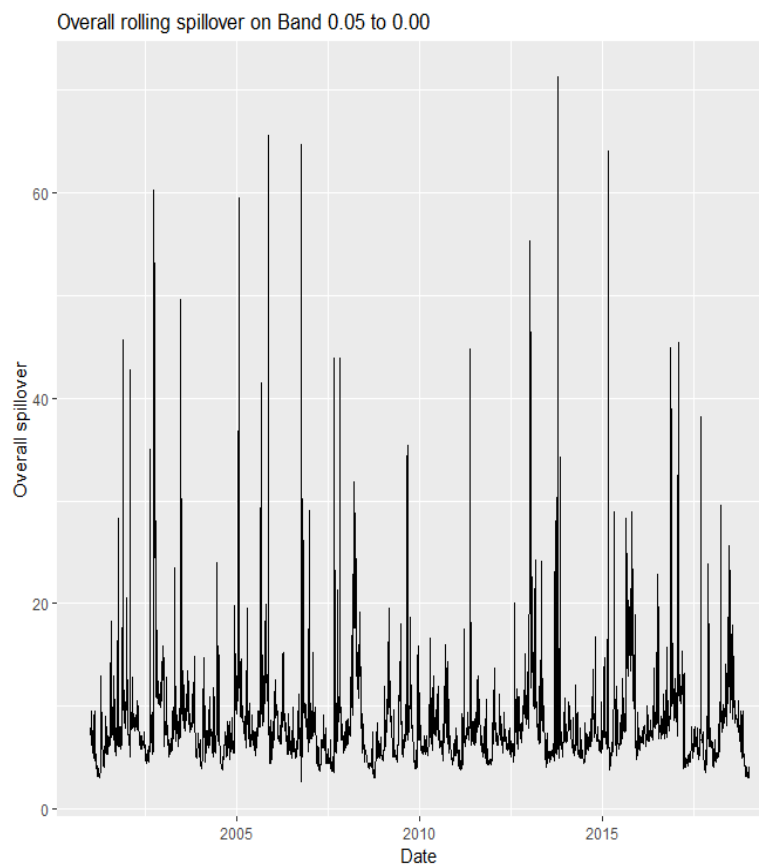

(a) Skewness (L3)

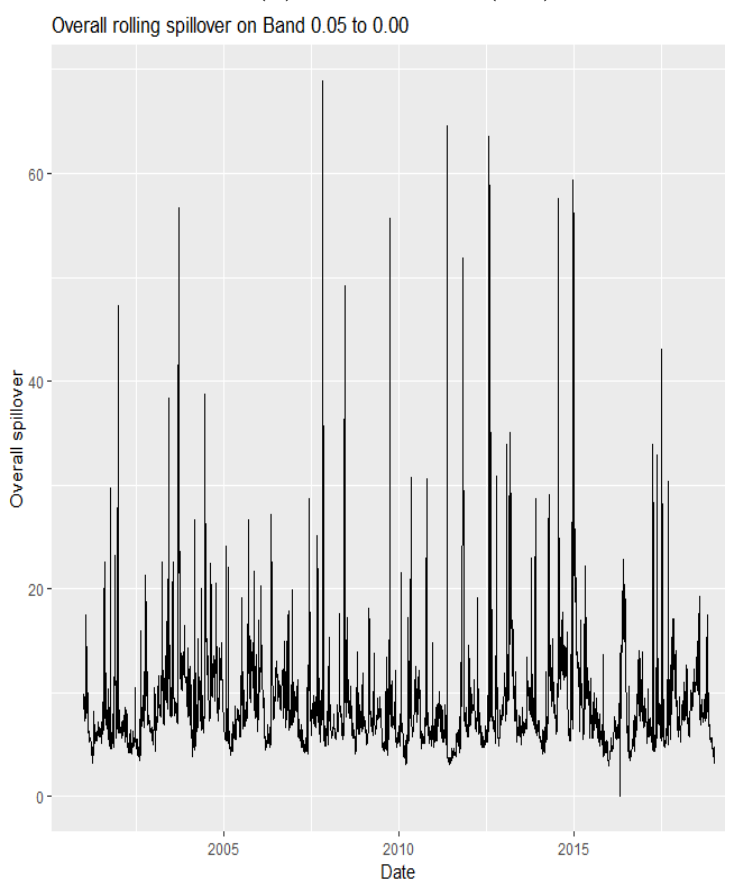

(b) Kurtosis (L4)

implications bordering on cross-market integration among themselves instead of with external countries like the US.

We confirm our shape shift-contagion hypothesis in the short-term as we evidence sudden increases in connectedness values between late 2016 and mid-2017 which are removed from the 2007-2009 GFC. Thus, traders and policy makers should look beyond crisis periods to contain consequences they bring. We also find connectedness to be both time-varying and frequency-dependent and hence should inform both policy and trading strategies accordingly.

\section{References}


Bae, K.-H., Karolyi, G. A., and Stulz, R. M. (2003) A New Approach to Measuring Financial Contagion, The Review of Financial Studies, 16(3), 717-763.

Bampinas, G., and Panagiotidis, T. (2017) Oil and stock markets before and after financial crises: A local Gaussian correlation approach, Journal of Futures Markets, 37(12), 11791204.

Baur, D. G. (2013) The structure and degree of dependence: A quantile regression approach, Journal of Banking and Finance, 37(3), 786-798.

Bessembinder, H. (2018) Do stocks outperform Treasury bills?, Journal of Financial Economics, 129(3), 440-457.

Boako, G., and Alagidede, P. (2016) Co-movement of Africa's equity markets: Regional and global analysis in the frequency-time domains, Physica A: Statistical Mechanics and Its Applications, 468.

Bodart, V., and Candelon, B. (2009) Evidence of interdependence and contagion using a frequency domain framework, Emerging Markets Review, 10(2), 140-150.

Boubaker, S., Jouini, J., and Lahiani, A. (2016) Financial contagion between the US and selected developed and emerging countries: The case of the subprime crisis, The Quarterly Review of Economics and Finance, 61, 14-28.

Chan, J. C. C., Fry-McKibbin, R. A., and Hsiao, C. Y.-L. (2019) A regime switching skewnormal model of contagion, Studies in Nonlinear Dynamics \& Econometrics, 23(1).

Diebold, F. X., and Yilmaz, K. (2009) Measuring Financial Asset Return and Volatility Spillovers, with Application to Global Equity Markets, The Economic Journal, 119(534), 158171.

Forbes, K. J., and Rigobon, R. (2002) No contagion, only interdependence: Measuring stock market comovements, The Journal of Finance, 57(5), 2223-2261.

Freimer, M., Kollia, G., Mudholkar, G. S., and Lin, C. T. (1988) A study of the generalized tukey lambda family, Communications in Statistics-Theory and Methods, 17(10), 35473567.

Fry-McKibbin, R., Hsiao, C., and Martin, V. L. (2017) Joint Tests of Contagion with Applications to Financial Crises (SSRN Scholarly Paper No. ID 2941178), retrieved from Social Science Research Network website: https://papers.ssrn.com/abstract=2941178

Karian, Z. A., and Dudewicz, E. J. (2016) Handbook of fitting statistical distributions with R, Florida, USA: CRC Press.

Martellini, L., and Ziemann, V. (2010) Improved Estimates of Higher-Order Comoments and Implications for Portfolio Selection, The Review of Financial Studies, 23(4), 1467-1502.

Martin, R. (2011) The local geographies of the financial crisis: From the housing bubble to economic recession and beyond, Journal of Economic Geography, 11(4), 587-618.

Meinusch, A. (2017) When the Fed sneezes: Spillovers from U.S. monetary policy to emerging markets (working Paper No. 30-2017), retrieved from Joint Discussion Paper Series in Economics website: https://www.econstor.eu/handle/10419/174326

Mollah, S., Quoreshi, A. M. M. S., and Zafirov, G. (2016) Equity market contagion during global financial and Eurozone crises: Evidence from a dynamic correlation analysis, Journal of International Financial Markets, Institutions and Money, 41, 151-167.

Müller, P., and Wagner, J. (2018) How do the consideration of non-normal return distributions and of higher moments influence the optimal asset allocation in Swiss pension funds? Zeitschrift Für Die Gesamte Versicherungswissenschaft, 1-15.

Müller, U. A., Dacorogna, M. M., Davé, R. D., Pictet, O. V., Olsen, R. B., and Ward, J. R. (1993) Fractals and intrinsic time: A challenge to econometricians, unpublished Manuscript, Olsen \& Associates, Zürich.

Pfaff, B. (2016) Financial risk modelling and portfolio optimization with R, West Sussex, UK: John Wiley \& Sons. 
Ramberg, J. S., and Schmeiser, B. W. (1974) An approximate method for generating asymmetric random variables, Communications of the ACM, 17(2), 78-82.

Saiti, B., Bacha, O. I., and Masih, M. (2016) Testing the conventional and Islamic financial market contagion: Evidence from wavelet analysis, Emerging Markets Finance and Trade, 52(8), 1832-1849.

Shahzad, S. J. H., Nor, S. M., Kumar, R. R., and Mensi, W. (2017) Interdependence and contagion among industry-level US credit markets: An application of wavelet and VMD based copula approaches, Physica A: Statistical Mechanics and Its Applications, 466, 310-324.

Støve, B., Tjøstheim, D., and Hufthammer, K. O. (2014) Using local Gaussian correlation in a nonlinear re-examination of financial contagion, Journal of Empirical Finance, 25, 62-82.

Tiwari, A. K., Cunado, J., Gupta, R., and Wohar, M. E. (2018) Volatility spillovers across global asset classes: Evidence from time and frequency domains, The Quarterly Review of Economics and Finance, 70, 194-202.

Tiwari, A. K., Shahbaz, M., Hasim, H. M., and Elheddad, M. M. (2019) Analysing the spillover of inflation in selected Euro-area countries, Journal of Quantitative Economics, 17(3), 551577.

Su, S. (2007. Numerical maximum log likelihood estimation for generalized lambda distributions, Computational Statistics \& Data Analysis, 51(8), 3983-3998.

Wang, G.-J., Xie, C., Lin, M., and Stanley, H. E. (2017) Stock market contagion during the global financial crisis: A multiscale approach. Finance Research Letters, 22, 163-168.

Yilmaz, K. (2010) Return and volatility spillovers among the East Asian equity markets. Journal of Asian Economics, 21(3), 304-313. 
Table 2. Total spillover and Net spillover indices between higher moments of the top 9 EMs and US equities.

\begin{tabular}{|c|c|c|c|c|c|c|c|c|c|c|c|c|}
\hline & \multicolumn{12}{|c|}{ Panel A - Skewness (L3) } \\
\hline & China & S. Korea & Taiwan & India & Brazil & S. Africa & Russia & Mexico & Thailand & US & FROM_ABS ${ }^{\mathrm{a}}$ & FROM_WTH ${ }^{\mathrm{b}}$ \\
\hline \multicolumn{13}{|c|}{ Spillover for band:3.14 to $0.79 ;$ corresponds to 1 days to 4 days } \\
\hline China & 15.58 & 0 & 0.02 & 0.04 & 0 & 0.02 & 0.02 & 0.03 & 0.01 & 0.03 & 0.02 & 0.09 \\
\hline S. Korea & 0.01 & 75.01 & d0.19 & 0.03 & 0 & 0 & 0.01 & 0.03 & 0.01 & 0.01 & 0.03 & 0.15 \\
\hline Taiwan & 0.02 & 0.01 & 11.66 & 0.01 & 0 & 0 & 0 & 0.01 & 0.01 & 0 & 0.01 & 0.04 \\
\hline India & 0.05 & 0.02 & 0.01 & 13.03 & 0.01 & 0 & 0.01 & 0.01 & 0 & 0.01 & 0.01 & 0.06 \\
\hline Brazil & 0.01 & 0 & 0 & 0 & 12.59 & 0.01 & 0 & 0.06 & 0.01 & 0 & 0.01 & 0.04 \\
\hline S. Africa & 0.01 & 0 & 0 & 0 & 0 & 12.58 & 0.01 & 0.02 & 0 & 0.01 & 0.01 & 0.03 \\
\hline Russia & 0.01 & 0 & 0 & 0.01 & 0.01 & 0.02 & 14.01 & 0.01 & 0 & 0.05 & 0.01 & 0.06 \\
\hline Mexico & 0 & 0 & 0 & 0 & 0.03 & 0.01 & 0.01 & 11.11 & 0 & 0 & 0.01 & 0.03 \\
\hline Thailand & 0.03 & 0 & 0.03 & 0 & 0.01 & 0.01 & 0.01 & 0 & 14.08 & 0.01 & 0.01 & 0.05 \\
\hline US & 0.01 & 0.01 & 0 & 0 & 0 & 0 & 0.01 & 0 & 0.01 & 13.04 & 0.01 & 0.03 \\
\hline TO_ABS ${ }^{\mathrm{a}}$ & 0.02 & 0.01 & 0.03 & 0.01 & 0.01 & 0.01 & 0.01 & 0.02 & 0.01 & 0.01 & 0.12 & \\
\hline $\mathrm{TO}^{-} \mathrm{WTH}^{\mathrm{b}}$ & 0.08 & 0.03 & 0.14 & 0.05 & 0.03 & 0.04 & 0.05 & 0.09 & 0.03 & 0.06 & & 0.60 \\
\hline Net & -0.002 & -0.023 & 0.019 & -0.002 & -0.002 & 0.002 & -0.002 & 0.010 & -0.004 & 0.005 & & \\
\hline \multicolumn{13}{|c|}{ Spillover for band: 0.05 to 0.00 ; corresponds to 64 infinite days } \\
\hline China & 11.59 & 0 & 0 & 0.35 & 0.03 & 0.03 & 0.01 & 0.01 & 0.13 & 0.01 & 0.06 & 0.45 \\
\hline S. Korea & 0.01 & 0.99 & 0 & 0 & 0.01 & 0 & 0.01 & 0 & 0 & 0.01 & 0 & 0.02 \\
\hline Taiwan & 0.01 & 0.02 & 15.53 & 0 & 0.02 & 0 & 0.04 & 0.01 & 0 & 0.06 & 0.02 & 0.13 \\
\hline India & 0.01 & 0 & 0.22 & 12.72 & 0.07 & 0.29 & 0.02 & 0.01 & 0 & 0.02 & 0.06 & 0.49 \\
\hline Brazil & 0.01 & 0 & 0.07 & 0 & 13.75 & 0.16 & 0.03 & 0.12 & 0 & 0.01 & 0.04 & 0.32 \\
\hline S. Africa & 0.06 & 0.02 & 0.23 & 0.09 & 0.01 & 14.27 & 0.17 & 0.01 & 0.05 & 0.1 & 0.07 & 0.56 \\
\hline Russia & 0.2 & 0.02 & 0.04 & 0.01 & 0.06 & 0.12 & 14.19 & 0.1 & 0 & 0 & 0.06 & 0.43 \\
\hline Mexico & 0.08 & 0 & 0 & 0.02 & 0.89 & 0.02 & 0.14 & 14.1 & 0.08 & 0.32 & 0.16 & 1.22 \\
\hline Thailand & 0.02 & 0 & 0.01 & 0.01 & 0.01 & 0.08 & 0.08 & 0.02 & 12.46 & 0.07 & 0.03 & 0.23 \\
\hline US & 0.03 & 0.01 & 0.01 & 0.08 & 0.1 & 0.02 & 0 & 0.03 & 0 & 13.25 & 0.03 & 0.23 \\
\hline TO_ABS ${ }^{a}$ & 0.04 & 0.01 & 0.06 & 0.06 & 0.12 & 0.07 & 0.05 & 0.03 & 0.03 & 0.06 & 0.52 & \\
\hline TO_WTH ${ }^{b}$ & 0.33 & 0.06 & 0.45 & 0.44 & 0.93 & 0.57 & 0.39 & 0.24 & 0.21 & 0.46 & & 4.09 \\
\hline Net & -0.015 & 0.004 & 0.041 & -0.006 & 0.078 & 0.001 & -0.005 & -0.125 & -0.002 & 0.030 & & \\
\hline
\end{tabular}

Note: ${ }^{a}$ Absolute to measures skewness/kurtosis spillovers from country $j$ to other countries. Absolute from measures skewness/kurtosis spillovers from other countries to country $j .{ }^{b}$ Within to measures skewness/kurtosis spillovers from country $j$ to other countries, including from own innovations to country $k$. Within from measures skewness/kurtosis spillovers from other countries to country $j$, including from own innovations to country $k$ (see Tiwari et al., 2018, 2019). The largest contributions of markets per frequency band are in bold italics. S. African and S. Korea represent South African and South Korea, respectively. Positive Net indicates that the market is a net transmitter while negative Net denoted net recipient market. 
Table 2 (cont'd). Total spillover and Net spillover indices between higher moments of the top 9 EMs and US equities.

\begin{tabular}{|c|c|c|c|c|c|c|c|c|c|c|c|c|}
\hline \multicolumn{13}{|c|}{ Panel B - Kurtosis (L4) } \\
\hline & China & S. Korea & Taiwan & India & Brazil & S. Africa & Russia & Mexico & Thailand & US & FROM_ABS ${ }^{\mathrm{a}}$ & FROM_WTH $^{\mathrm{b}}$ \\
\hline \multicolumn{13}{|c|}{ Spillover for band: 3.14 to 0.79 ; corresponds to 1 days to 4 days } \\
\hline China & 12.6 & 0 & 0.01 & 0.05 & 0 & 0.01 & 0.01 & 0.02 & 0.01 & 0 & 0.01 & 0.05 \\
\hline S. Korea & 0 & 75.13 & 0.03 & 0.02 & 0 & 0 & 0.03 & 0 & 0.02 & 0.03 & 0.01 & 0.07 \\
\hline Taiwan & 0.01 & 0 & 13.25 & 0.01 & 0.01 & 0 & 0 & 0 & 0.02 & 0 & 0.01 & 0.03 \\
\hline India & 0.04 & 0.01 & 0.01 & 14.54 & 0.04 & 0.01 & 0 & 0.01 & 0.01 & 0 & 0.01 & 0.07 \\
\hline Brazil & 0.03 & 0 & 0.02 & 0.04 & 20.5 & 0.04 & 0 & 0.04 & 0 & 0.02 & 0.02 & 0.1 \\
\hline S. Africa & 0.01 & 0 & 0.02 & 0 & 0.01 & 12.8 & 0.03 & 0.03 & 0 & 0 & 0.01 & 0.05 \\
\hline Russia & 0.01 & 0 & 0 & 0 & 0 & 0.01 & 13.39 & 0.02 & 0 & 0 & 0.01 & 0.03 \\
\hline Mexico & 0.01 & 0 & 0 & 0 & 0.03 & 0.02 & 0.02 & 13.24 & 0 & 0.07 & 0.02 & 0.08 \\
\hline Thailand & 0 & 0.02 & 0.03 & 0.01 & 0 & 0 & 0 & 0 & 12.24 & 0.01 & 0.01 & 0.04 \\
\hline US & 0.01 & 0 & 0 & 0 & 0 & 0 & 0 & 0.06 & 0.01 & 12.63 & 0.01 & 0.05 \\
\hline TO_ABS ${ }^{a}$ & 0.01 & 0 & 0.01 & 0.01 & 0.01 & 0.01 & 0.01 & 0.02 & 0.01 & 0.01 & 0.11 & \\
\hline TO_WTH ${ }^{b}$ & 0.07 & 0.02 & 0.06 & 0.06 & 0.05 & 0.05 & 0.04 & 0.09 & 0.04 & 0.07 & & 0.56 \\
\hline Net & 0.003 & -0.010 & 0.007 & 0.003 & 0.003 & 0.001 & -0.001 & -0.011 & 0.000 & 0.004 & & \\
\hline \multicolumn{13}{|c|}{ Spillover for band: 0.05 to $0.00 ;$ corresponds to 64 infinite days } \\
\hline China & 13.99 & 0 & 0.01 & 0.01 & 0.01 & 0.63 & 0 & 0 & 0.07 & 0 & 0.07 & 0.6 \\
\hline S. Korea & 0.01 & 0.99 & 0 & 0 & 0 & 0 & 0 & 0.01 & 0 & 0 & 0 & 0.02 \\
\hline Taiwan & 0.04 & 0.02 & 14.31 & 0 & 0.09 & 0.09 & 0.04 & 0.02 & 0 & 0.1 & 0.04 & 0.31 \\
\hline India & 0.01 & 0 & 0.05 & 11.31 & 0.03 & 0 & 0 & 0 & 0.02 & 0 & 0.01 & 0.09 \\
\hline Brazil & 0.08 & 0 & 0 & 0.04 & 9.73 & 0.06 & 0.12 & 0.34 & 0.03 & 0 & 0.07 & 0.55 \\
\hline S. Africa & 0.01 & 0 & 0.03 & 0.03 & 0.05 & 13.96 & 0.01 & 0.02 & 0 & 0 & 0.01 & 0.12 \\
\hline Russia & 0.52 & 0 & 0 & 0.01 & 0.01 & 0.18 & 13.07 & 0.19 & 0.02 & 0.08 & 0.1 & 0.82 \\
\hline Mexico & 0.07 & 0 & 0.01 & 0.02 & 0.34 & 0.2 & 0.04 & 12.84 & 0.02 & 0.36 & 0.11 & 0.86 \\
\hline Thailand & 0.08 & 0 & 0.06 & 0.02 & 0.01 & 0.49 & 0.06 & 0 & 14.32 & 0.01 & 0.07 & 0.58 \\
\hline US & 0 & 0 & 0 & 0.03 & 0.05 & 0.05 & 0.01 & 0.36 & 0.02 & 14.11 & 0.05 & 0.42 \\
\hline TO_ABS ${ }^{a}$ & 0.08 & 0 & 0.02 & 0.01 & 0.06 & 0.17 & 0.03 & 0.09 & 0.02 & 0.06 & 0.54 & \\
\hline $\mathrm{TO}_{-}^{-} \mathrm{WTH}^{\mathrm{b}}$ & 0.65 & 0.03 & 0.14 & 0.12 & 0.47 & 1.38 & 0.22 & 0.76 & 0.15 & 0.45 & & 4.36 \\
\hline Net & 0.006 & 0.001 & -0.022 & 0.004 & -0.010 & 0.157 & -0.074 & -0.012 & -0.054 & 0.004 & & \\
\hline
\end{tabular}

Note: ${ }^{a}$ Absolute to measures skewness/kurtosis spillovers from country $j$ to other countries. Absolute from measures skewness/kurtosis spillovers from other countries to country $j .{ }^{b}$ Within to measures skewness/kurtosis spillovers from country $j$ to other countries, including from own innovations to country $k$. Within from measures skewness/kurtosis spillovers from other countries to country $j$, including from own innovations to country $k$ (see Tiwari et al., 2018, 2019). The largest contributions of markets per frequency band are in bold italics. S. African and S. Korea represent South African and South Korea, respectively. Positive Net indicates that the market is a net transmitter while negative Net denoted net recipient market. 